\title{
Trisomy 19 as the sole chromosomal abnormality in CML
}

\author{
Salil N. Vaniawala, Pankaj K. Gadhia* \\ Molecular Cytogenetic Unit, S. N. Gene Laboratory and Research Centre, President Plaza - A, Near RTO Circle, Surat, India \\ Email address: \\ pankajkgadhia@gmail.com (P. K. Gadhia), sali1@sngenelab.com (S. N. Vaniawala)
}

To cite this article:

Salil N. Vaniawala, Pankaj K. Gadhia. Trisomy 19 as the Sole Chromosomal Abnormality in CML. International Journal of Genetics and Genomics. Vol. 2, No. 4, 2014, pp. 77-79. doi: 10.11648/j.ijgg.20140204.15

\begin{abstract}
Presence of trisomy 19 in chronic myeloid leukemia (CML) normally considered as secondary abnormality but trisomy 19 rarely occur as sole abnormality. In the present study a total of $2312 \mathrm{Ph}$ positive CML were screened from year2004 to 2014 and we found 2 cases of trisomy 19 as sole karyotype abnormalities. Both karyotype showed $47, \mathrm{XY}, \mathrm{t}(9 ; 22)(\mathrm{q} 34 ; \mathrm{q} 11.2),+19$, complements. It is not known that which gene(s) present on chromosome 19 plays important role in development of this condition.
\end{abstract}

Keywords: Trisomy 19, Sole Chromosome Abnormality, CML

\section{Introduction}

Chronic myeloid leukemia (CML) is characterised by the Philadelphia chromosome $(\mathrm{Ph})$ which is originated by a balanced translocation between chromosome 9 and 22 that is $\mathrm{t}(9 ; 22)(\mathrm{q} 34 ; \mathrm{q} 11.2)$ in more than $90 \%$ of the patients. The crucial pathogenetic consequence of this translocation is the creation of a chimeric $\mathrm{BCR} / \mathrm{ABL}$ gene on derivative chromosome 22[1]. This chimeric protein is associated with an increased tyrosine kinase activity which plays an important role in pathogenesis of CML [2].

Trisomy 19 as a sole abnormality is a rare event normally associated with myeloid malignancies and it was described involving various hematological malignancies [3].

The occurrence of additional chromosomal aberrations (ACA) in Ph-positive CML is strongly associated with disease progression and involved in clonal evolution and chromosomal instability $[4,5]$.

During our screening, we encountered two cases in which trisomy 19 occurred as the sole abnormality. In the present case report we describe in detail clinical and cytogenetic findings of two patients with CML positive and +19 as a sole anomaly.
Case - 1

A 34 year old male patient's blood/bone-marrow was received for diagnosis of CML. His complete blood cell count revealed an $\mathrm{Hb}$ concentration $8.3 \mathrm{X} \mathrm{g} / \mathrm{dL}$, platelet count $310 \times 10^{9} / \mathrm{L}$ and a WBC $8.1 \times 10^{9}$ with $85 \%$ blast and bone-marrow recorded to have $93 \%$ blast. Cytogenetic analysis was performed using one part directly terminated and other part was incubated in Marrow max medium for 18 to 20 hours. G-banding was performed and G-banded karyotype was prepared according to guidelines of International Sysytem for Human Cytogenetics Nomenclature (ISCN)(2009 \& 2013)[6]. His karyotyped showed 47, XY, t(9;22)(q34;q11.2),+19 (Fig.-1).

Case - 2

A 23 year old male was referred to our laboratory for diagnosis of CML.

His blood picture revealed $\mathrm{Hb} 7.2 \mathrm{~g} / \mathrm{dL}$, a platelet count was $230 \times 10^{9 /} \mathrm{L}$, a WBC

Of $6.3 \times 10^{9} / \mathrm{L}$. Bone marrow showed only $45 \%$ blast cells. Cytogenetic analysis of bone-marrow showed 47,XY,t(9;22)(q34; q11.2).+19 (Fig.-2) 


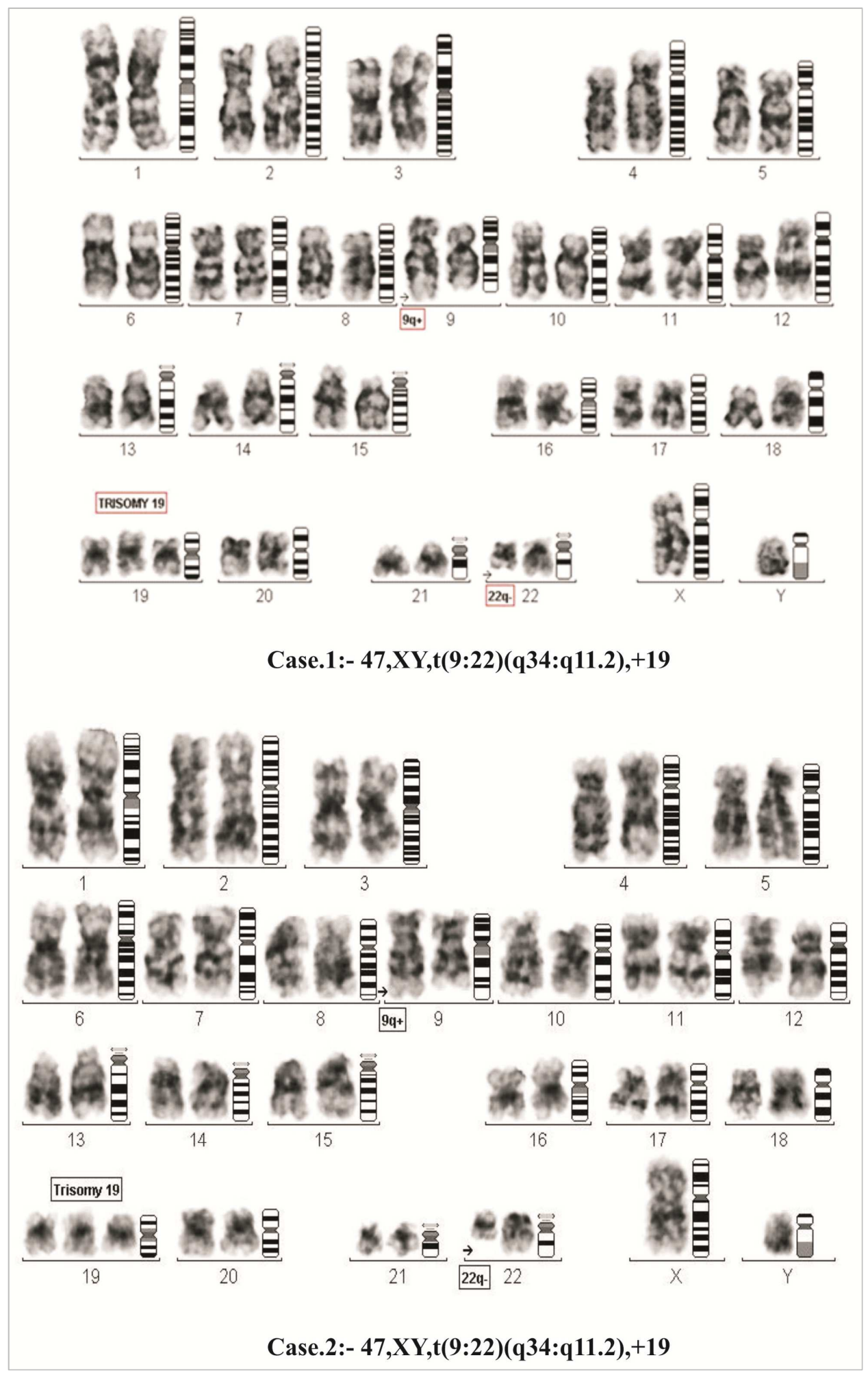

Figs. 1\& 2. G-banded karyotyped of CML patient showing trisomy 19

\section{Results and Discussion}

Our data base search revealed a total of 2312 adult case of $\mathrm{Ph}$ positive CML between 2004 to 2014. Of which, we found only 2 cases of +19 as sole cytogenetic abnormalities along with CML (Figs. 1\&2). It is reported that sole cytogenetic abnormalities have received attention because the term sole refers not only to the first cytogenetic changes to occur in neoplastic cells, but also their important role in tumorigenesis [3,7].

It is well known that trisomy 19 is associated with myeloid malignancies, however, the presence of trisomy 19 
as sole karyotypic aberrations is rare and it has been only reported in 48 hematopoietic malignancies [8].

The biologic relevance of trisomy 19 may relate to a gene dosage effect. For example, the human DNA methyltransferase 1 gene has been mapped to the short arm of chromosome 19 (19p13.2)[9] which catalyses "maintenance" methylation of mammalian genomic DNA. It is still unclear which gene(s) located on chromosome 19 might have a functional role in the development of hematologic malignancies.

We conclude based on clinical data and cytogenetic study where presence of positive chromosome Philadelphia and Trisomy 19 in two cases only. It is a very small number looking to total number of CML positive cases in the span of ten years. Therefore sole chromosome abnormality of trisomy 19 has clinical implications and prognostic outcome and hence isolated trisomy 19 require further detailed research.

\section{Acknowledgment}

Authors sincerely wish to thank Mr. Urvish Dalal for his assistance in photography

\section{References}

[1] R. La Sturza, N. Testoni, M. Lafage-Pochitaloff, D.Ruggeri, E. Ottaviani, G. Perla et al., "Complex variant Philadelphia translocation involving the Short arm of chromosome 6 in CML.” Hematologica, Vol. 87, pp. 143-47 2002.
[2] T.G.Lugo, A.M. Pendergast, A. J. Muller, O.N. Witte, "Tyrosine kinase activity and transformation potency of bcrabl oncogene products. Science, Vol. 247, pp. 1079-82, 1990.

[3] I.L.Soon, H.S.Cho, C.H.Lee, K. D. Kim, J. K.Ha, M.K. Kim, K.H. Lee, M.S.Hyun, "Two cases of Trisomy19 as a sole chromosomal abnormality in myeloid disorders". Kor. J. Lab. Med, Vol. 28, pp. 174 - 178, 2008.

[4] B. Johansson, T. Fioretos, F. Mitelman, "cytogenetic and molecular genetic evolution of chronic myeloid leukemia" Acta Hematol, Vol. 107(2), pp.76-94, 2002.

[5] J. L. Diez-Martin, G.W. Dewald, R. V. Pierre, "Possible cytogenetic distinction between lymphoid and myeloid blast crisis in chronic granulocytic leukemia" Am. J. Hematol, Vol. 27, pp. 194-203, 1988.

[6] International System for Human Cytogenetics Nomenclature (ISCN), S. Karger Pub. Inc. 2009, 2013.

[7] S. Luatti, F.castagnetti, G.Marzocchi, C. Bladdazi, G. Gugliotta, I. Lacobucci et al., "Additional chromosomal abnormalities in Philadelphia-positive clone: adverse prognostic influence on frontline imatinib therapy: a GIMEMA working party on CML analysis", Blood, Vol. 120(4), pp. 716-67, 2012.

[8] M. Daskalkis, N. Mauritzson, B. Johansson, K. Bouabdallah, F. Onida, R. Kunzamann, H. Muller-Berndroff, A. SchmidtGraff, M. Lubbert, "Trisomy 19 as the sole chromosomal abnormality in proliferative chronic myelomonocytic leukemia”. Leukemia Res. Vol. 30, pp. 1043-47, 2006.

[9] R.W. Yen, P.M. Vertino, B.D. Nelkin, J.J. Yu, W. El-Deiry, A Cumarswamy, "Isolation and characterization of c-DNA encoding human DNA methyl-transferase", Nucleic acid Res. Vol. 20(9), pp. 2289-91, 1992. 